\title{
Numerical Investigation of Simultaneous Injection of Pulverized Coal and Natural Gas with Oxygen Enrichment to the Blast Furnace
}

\author{
Jose Adilson de CASTRO, Hiroshi NOGAMI" and Jun-ichiro YAGI ${ }^{11}$ \\ Programa de pós Graduação em Engenharia Metalúrgica, Universidade Federal Fluminense, EEIMVR. Av. dos Trabalhadores, \\ 420, Volta Redonda, Rio de Janeiro, Brasil. E-mail: adilson@metal.eeimvr.uff.br \\ 1) Institute of Multidisciplinary Research for Advanced Materials, Tohoku University, Katahira, Aoba-ku, Sendai $980-8577$ \\ Japan. E-mail: yagi@iamp.tohoku.ac.jp
}

(Received on March 15, 2001; accepted in final form on July 1, 2002)

\begin{abstract}
The multiple injection of carbonaceous materials and oxygen enrichment in the blast furnace has received especial attention in the recent years due to its possibility of considerably decrease in coke rate and increase of the productivity. This paper introduces a modeling of the co-injection of pulverized coal and natural gas into the blast furnace through the tuyere. This model treats the blast furnace as a multi-phase reactor and five phases are treated simultaneously: gas, lump solids (iron ore, sinter, pellets and coke), pig iron, molten slag and pulverized coal. Conservation equations for mass, momentum, energy and chemical species are solved simultaneously based on the finite volume method. Firstly pulverized coal is simulated and afterwards only natural gas is investigated and compared with the all coke operation. Finally, the combined practice is suggested in order to improve the actual blast furnace operation. The simulation results have contributed to better understanding the blast furnace phenomena with multiple injectants, and supported new improvements in the furnace operation. The results obtained in this investigation have shown the possibility of considerable advances in the actual blast furnace operation such as increase in productivity, lower silicon content in hot metal and decrease of the coke and slag rates. In addition, the total amount of the greenhouses in the off gas is decreased, which contributes to make the blast furnace process cleaner.
\end{abstract}

KEY WORDS: blast furnace; mathematical model; multi-phase flow; pulverized coal injection; natural gas injection; chemical reactions.

\section{Introduction}

The ironmaking process is one of the most energy consuming in the metallurgical industries. In the integrated route of steel production the blast furnace represents about $70 \%$ of the energy input. About $30 \%$ of the total cost of pig iron production are due to the fuels used in the blast furnace. Therefore, tremendous efforts have been made in order to reduce the fuel rate of the blast furnace, or at least, replace the coke consumption by less noble fuels injected through the blast furnace tuyere, like pulverized coal, tar, oil, natural gas and so on. This has contributed to decrease the hot metal cost and improve the blast furnace performance. The pulverized coal injection technology has achieved maturity and several blast furnaces over the world have been operated with pulverized coal rates over $200 \mathrm{~kg} / \mathrm{thm}$. However, natural gas injection has been restricted to regions where this energy source is abundant, in spite of the recognized advantages of natural gas injection to the blast furnace process such as high productivity and environmentally cleaner. The injection of natural gas in the blast furnace tuyere substitutes coke charged from the blast furnace top and furnishes high amount of hydrogen, which replaces carbon monoxide as reducing gas in the shaft of the blast furnace. The hydrogen gas is a better reducing gas compared with carbon monoxide and allows savings of energy by decreasing the amount of direct reduction, which demands considerable amount of energy for the reaction. Another notable benefit is the prevention of the global warming, since water is generated instead of carbon dioxide. In addition, the technology of natural gas injection calls for practically no capital investment or special equipment compared with pulverized coal injection. The main investment required for the natural gas injection is regarded as the gas distributor and pressure equalizer, which doesn't represent high investment, compared with the pulverized injection and other carbonaceous injection. Due to these advantages, about $80 \%$ of the former USSR, USA and Canada blast furnaces operate with natural gas ranges from 30 up to $120 \mathrm{~kg} / \mathrm{thm}$. Babich et al. ${ }^{1)}$ investigated several possibilities of combined injection of natural gas and pulverized coal in the blast furnace and showed optimum conditions for operating the blast furnace with such injectants, however his analysis was based on the total energy and mass balance without considering in-furnace conditions. Also several trials of high rates of natural gas injection have 
been successfully carried out at ACME in the USA. ${ }^{2-4)}$ Other studies have been carried out in blast furnaces, which operate with natural gas. ${ }^{2-5)}$ However, a detailed mathematical model, which is capable of simulating the multiple injection through the blast furnace tuyere, has yet to be considered. In this paper a mathematical model of the blast furnace is presented to simulate the blast furnace operation with multiple injection of pulverized coal and natural gas with the blast enriched by oxygen. Simulations are carried out in order to compare the in-furnace response for high rates of natural gas and pulverized coal injection. The model is based on the multi-fluid theory ${ }^{6-8)}$ and considers explicitly five phases (gas, lump solid, molten metal, molten slag and pulverized coal). Each phase has its own composition and properties, and reactions involving all phases are considered in order to simulate the process of multiple injection.

\section{Modeling}

\subsection{General Conservation Equation}

The mathematical model is two dimensional and axisymmetric. It analyses the packed bed region within the blast furnace, from the surface of the slag in the hearth up to the burden surface in the throat. Five phases are treated (gas, lump solids, hot metal, slag and pulverized coal). All phases are treated simultaneously due to mutual interactions. Thus, the governing equations of all phases, that form a large set of strongly coupled non linear equations, are solved simultaneously. In this model, the conservation equations for the natural gas species are newly introduced to the gas phase and the chemical reactions and physical properties are also considered.

Governing conservation equations for all phases are expressed via a general equation, represented by Eq. (1), which is independent of the coordinate system.

$$
\frac{\partial\left(\varepsilon_{i} \rho_{i} \phi_{i}\right)}{\partial t}+\operatorname{div}\left(\varepsilon_{i} \rho_{i} \vec{V}_{i} \phi_{i}-\varepsilon_{i} \Gamma_{\phi_{i}} \operatorname{grad} \phi_{i}\right)=S_{\phi_{i}}
$$

In this equation, $i$ represents the phase being considered. $\Gamma_{\phi_{i}}$ is the effective transfer coefficient which assumes different meaning for each dependent variable to be solved. The source terms are due to inter-phase interactions that can be through chemical reactions, surface interactions and external force. Each phase contains several chemical species and the general conservation equation is used to calculate the phase motion, energy and composition. The list of all species treated in this model is presented in Table 1, including the newly introduced chemical species in the gas phase to consider the natural gas injection.

\subsection{Behavior of Natural Gas in the Blast Furnace}

The source terms in the conservation equations take into account chemical reactions, interactions, external forces, phase changes and so on. The continuity and species equations have mass sources due to chemical reactions and phase transformations. Enthalpy sources arise from interphase heat transfer, heat of reaction and sensible heat accompanying mass transfer due to chemical reactions and phase transformations. The formulations for the phase interactions and chemical reaction have been published in
Table 1. Phases and chemical species considered in the model.

\begin{tabular}{|c|c|c|}
\hline Phases & \multicolumn{2}{|c|}{ Chemical species } \\
\hline Gas & $\mathrm{CO}, \mathrm{CO}_{2}, \mathrm{O}_{2}, \mathrm{H}_{2}, \mathrm{H}_{2} \mathrm{O}, \mathrm{N}_{2}, \mathrm{SiO}, \mathrm{CH}_{4}, \mathrm{C}_{2} \mathrm{H}_{6}, \mathrm{C}_{3} \mathrm{H}_{8}, \mathrm{C}_{4} \mathrm{H}_{10}$ \\
\hline \multirow{4}{*}{ Solid } & ore & $\mathrm{Fe}_{2} \mathrm{O}_{3}, \mathrm{Fe}_{3} \mathrm{O}_{4}, \mathrm{FeO}, \mathrm{Fe}, \mathrm{CaO}, \mathrm{Al}_{2} \mathrm{O}_{3}, \mathrm{MgO}, \mathrm{SiO}_{2}, \mathrm{H}_{2} \mathrm{O}$, gangue \\
\cline { 2 - 3 } & sinter & $\mathrm{Fe}_{2} \mathrm{O}_{3}, \mathrm{Fe}_{3} \mathrm{O}_{4}, \mathrm{FeO}, \mathrm{Fe}, \mathrm{CaO}, \mathrm{Al}_{2} \mathrm{O}_{3}, \mathrm{MgO}, \mathrm{SiO}_{2}, \mathrm{H}_{2} \mathrm{O}$, gangue \\
\cline { 2 - 3 } & pellets & $\mathrm{Fe}_{2} \mathrm{O}_{3}, \mathrm{Fe}_{3} \mathrm{O}_{4}, \mathrm{FeO}, \mathrm{Fe}, \mathrm{CaO}, \mathrm{Al}_{2} \mathrm{O}_{3}, \mathrm{MgO}, \mathrm{SiO}_{2}, \mathrm{H}_{2} \mathrm{O}$, gangue \\
\cline { 2 - 3 } & coke & $\mathrm{C}, \mathrm{SiC}, \mathrm{SiO}_{2}, \mathrm{Al}_{2} \mathrm{O}_{3}, \mathrm{CaO}, \mathrm{MgO}, \mathrm{H}_{2} \mathrm{O}$, gangue \\
\hline Hot metal & $\mathrm{Fe}, \mathrm{C}, \mathrm{Si}$ \\
\hline Slag & $\mathrm{FeO}, \mathrm{SiO}_{2}, \mathrm{Al}_{2} \mathrm{O}_{3}, \mathrm{CaO}, \mathrm{MgO}$, gangue \\
\hline PC & $\mathrm{C}, \mathrm{SiO}_{2}, \mathrm{Al}_{2} \mathrm{O}_{3}, \mathrm{CaO}, \mathrm{MgO}$, volatiles \\
\hline
\end{tabular}

previous reports. ${ }^{6-8)}$ In this section, details of chemical reactions of the natural gas injected in the blast furnace through the tuyeres are explained, which are newly introduced in this model.

The natural gas injected through the blast furnace tuyeres is mixed with the gas stream and combusts partially in the interior of the tuyere and finally is completely combusted in the raceway. The mixing ratio of the natural gas with the blast within the tuyere plays an important role in the efficiency of the combustion in this zone. Therefore, especial techniques like counter flow or perpendicular injections are often used in order to improve the mixing ratio and hence suppress soot generation. ${ }^{1,3)}$

Natural gas combustion generates mainly $\mathrm{CO}$ and $\mathrm{H}_{2}$ as products under the raceway conditions and the gas volume in the blast furnace increases considerably. Also the thermophysical properties of gas phase are strongly affected by introducing natural gas in the blast furnace operation practice, since the amount of hydrogen in the gas phase inside the blast furnace increases. In addition, the ore/coke ratio in the burden materials increases. Therefore all the phase interactions such as momentum, mass transfer and energy exchanges are strongly affected when compared with pulverized coal or all coke operation. The calorific value of the natural gas is lower than that of pulverized coal. However, the high concentration of hydrogen in the gas phase promotes efficient reduction in the shaft with less energy consumption (heat of reaction for complete reduction by $\mathrm{CO}$ and $\mathrm{H}_{2}$ ). Table 2 presents a comparison of the energy needs for the complete reduction of hematite and shows clearly the advantage of complete reduction in the solid phase and avoids the direct reduction in the liquid phase, which is a strongly endothermic. Therefore the role of natural gas for ensure the complete reduction of the ore in the solid phase is determinant of the decrease of energy consumption of the blast furnace. Moreover, the direct reduction of molten wustite is expected to decrease considerably and compensates deleterious effects with lower slag rate, higher productivity, lower silicon content in the hot metal and so on. Natural gas as a gaseous fuel doesn't generates slag, on the contrary, coke and pulverized coal demand additional energy of melting the ash and deteriorates the flowing conditions in the raceway due to liquid generation.

In Table 3 a list of the chemical reactions and rate equations for the natural gas combustion is presented. The natural gas is considered to composed of mainly methane, ethane, butane and propane. These hydrocarbon in the presence of $\mathrm{O}_{2}$ combust to $\mathrm{CO} / \mathrm{CO}_{2}$ and $\mathrm{H}_{2} / \mathrm{H}_{2} \mathrm{O}$. The $\mathrm{CO}_{2}$ and $\mathrm{H}_{2} \mathrm{O}$ react with carbon of coke and pulverized coal or with 
Table 2. Energy consumption for the possible mechanism of pig iron production in the blast furnace process.

\begin{tabular}{|c|c|}
\hline Reduction mechanism & $\begin{array}{l}\text { Energy consumption } \\
{[\mathrm{Kcal} / \mathrm{kmol} \mathrm{Fe} 2 \mathrm{O} 3(\mathrm{~s})]}\end{array}$ \\
\hline 1) $\mathrm{Fe}_{2} \mathrm{O}_{3}(\mathrm{~s}) \stackrel{\mathrm{CO}}{\longrightarrow} \mathrm{Fe}_{3} \mathrm{O}_{4}(\mathrm{~s}) \stackrel{\mathrm{CO}}{\longrightarrow} \mathrm{Fe}_{\mathrm{w}} \mathrm{O}(\mathrm{s}) \stackrel{\mathrm{CO}}{\longrightarrow} \mathrm{Fe}(\mathrm{s}) \stackrel{\text { melt }}{\longrightarrow} \mathrm{Fe}(\mathrm{l})$ & $\Delta \mathrm{H}=+20305$ \\
\hline 2) $\mathrm{Fe}_{2} \mathrm{O}_{3}(\mathrm{~s}) \stackrel{\mathrm{H}_{2}}{\longrightarrow} \mathrm{Fe}_{3} \mathrm{O}_{4}(\mathrm{~s}) \stackrel{\mathrm{H}_{2}}{\longrightarrow} \mathrm{Fe}_{\mathrm{w}} \mathrm{O}(\mathrm{s}) \stackrel{\mathrm{H}_{2}}{\longrightarrow} \mathrm{Fe}(\mathrm{s}) \stackrel{\text { melt }}{\longrightarrow} \mathrm{Fe}(\mathrm{l})$ & $\Delta \mathrm{H}=+32977$ \\
\hline 3) $\mathrm{Fe}_{2} \mathrm{O}_{3}(\mathrm{~s}) \stackrel{\mathrm{CO}}{\longrightarrow} \mathrm{Fe}_{3} \mathrm{O}_{4}(\mathrm{~s}) \stackrel{\mathrm{CO}}{\longrightarrow} \mathrm{Fe}_{\mathrm{w}} \mathrm{O}(\mathrm{s}) \stackrel{\text { melt }}{\longrightarrow} \mathrm{Fe}_{\mathrm{w}} \mathrm{O}(\mathrm{l}) \stackrel{\mathrm{C}(\mathrm{s})}{\longrightarrow} \mathrm{Fe}(\mathrm{l})$ & $\Delta \mathrm{H}=+412468$ \\
\hline 4) $\mathrm{Fe}_{2} \mathrm{O}_{3}(\mathrm{~s}) \stackrel{\mathrm{H}_{2}}{\longrightarrow} \mathrm{Fe}_{3} \mathrm{O}_{4}(\mathrm{~s}) \stackrel{\mathrm{H}_{2}}{\longrightarrow} \mathrm{Fe}_{\mathrm{w}} \mathrm{O}(\mathrm{s}) \stackrel{\text { melt }}{\longrightarrow} \mathrm{Fe}_{\mathrm{w}} \mathrm{O}(\mathrm{l}) \stackrel{\mathrm{C}(\mathrm{s})}{\longrightarrow} \mathrm{Fe}(\mathrm{l})$ & $\Delta \mathrm{H}=+404428$ \\
\hline
\end{tabular}

Table 3. Chemical reaction considered for the combustion mechanism of the natural gas in the blast furnace model. ${ }^{9-11)}$

\begin{tabular}{|l|}
\hline $\mathrm{CH}_{4}(\mathrm{~g})+\frac{1}{2} \mathrm{O}_{2}(\mathrm{~g}) \rightarrow \mathrm{CO}(\mathrm{g})+2 \mathrm{H}_{2}(\mathrm{~g}) ; R_{2}=f_{1} k_{2} P_{\mathrm{CH}_{4}} P_{\mathrm{O}_{2}}^{1 / 2} ; k_{2}=2.17 \times 10^{12} \exp \left[-\frac{53670}{R T_{\mathrm{g}}}\right]$ \\
\hline $\mathrm{CH}_{4}(\mathrm{~g})+2 \mathrm{O}_{2}(\mathrm{~g}) \rightarrow \mathrm{CO}_{2}(\mathrm{~g})+2 \mathrm{H}_{2} \mathrm{O}(\mathrm{g}) ; R_{3}=\left(1-f_{1}\right) k_{2} P_{\mathrm{CH}_{4}} P_{\mathrm{O}_{2}}^{2} ; f_{0}=\exp \left[-\frac{12400}{1.987 T_{\mathrm{g}}}\right] ; f_{1}=\frac{f_{0}}{1+f_{0}}(3)$ \\
\hline $\mathrm{CH}_{4}(\mathrm{~g})+\mathrm{CO}_{2}(\mathrm{~g}) \rightarrow 2 \mathrm{CO}(\mathrm{g})+2 \mathrm{H}_{2}(\mathrm{~g}) ; R_{4}=k_{4} P_{\mathrm{CH}_{4}} P_{\mathrm{CO}_{2}} ;_{k_{4}}=3.01 \times 10^{10} \exp \left[-\frac{55685}{R T_{\mathrm{g}}}\right]$
\end{tabular}

hydrocarbon of the natural gas and finally generates $\mathrm{CO}$ and $\mathrm{H}_{2}$.

\section{Results and Discussions}

\subsection{Calculating Conditions}

The effect of natural gas and pulverized coal is investigated and compared with "all coke" operation. Also the simultaneous injection of natural gas and pulverized coal is considered in this section. Four cases are analyzed in this paper. The first case is regard as a base case where only coke is charged as fuel (all coke operation). The second case high rate of pulverized coal and additional oxygen is injected through the tuyere. In another case the effect of high rate of natural gas is investigated. And finally, the simultaneous injection of natural gas and pulverized coal is studied. Table 4 shows the main operational conditions for the four cases analyzed. The model assumes as essential boundary conditions for the calculation: 1) the blast conditions (composition, flow rate and temperature) at the tuyere inlet. 2) burden distribution conditions at the burden surface. As burden distribution is meant the burden distribution pattern of solids volume fraction, diameter of solids and composition of each species of the solid phase. The
Table 4. Operational parameters for the cases investigated.

\begin{tabular}{|c|c|c|c|c|}
\hline parameters & Coke & $\mathrm{PC}$ & NG & $\mathrm{NG}+\mathrm{PC}$ \\
\hline Natural gas (kg/thm) & - & - & 210.1 & 91.2 \\
\hline PCR $(\mathrm{kg} / \mathrm{thm})$ & - & 189.5 & - & 99.9 \\
\hline Coke rate $(\mathrm{kg} / \mathrm{thm})$ & 512.4 & 307.8 & 304.7 & 282.4 \\
\hline Fuel rate $(\mathrm{kg} / \mathrm{thm})$ & 512.4 & 497.3 & 514.8 & 473.5 \\
\hline Blast temperature $\left({ }^{\circ} \mathrm{C}\right)$ & 1198 & 1198 & 1198 & 1198 \\
\hline Blast $(\mathrm{Nm} 3 / \mathrm{h})$ & 10054 & 10117 & 10495 & 10621 \\
\hline Blast (Nm3/thm) & 1178 & 1168 & 942.5 & 897.6 \\
\hline Oxygen (Nm3/h) & 2301 & 2364 & 2742 & 2868 \\
\hline Oxygen $(\mathrm{Nm} 3 / \mathrm{thm})$ & 269.7 & 272.7 & 246.2 & 242.3 \\
\hline Oxygen enrichment $(\%)$ & 1.89 & 2.37 & 5.13 & 6.0 \\
\hline
\end{tabular}

burden distribution patterns for all cases are presented in Fig. 1 and used as boundary conditions for the calculations. The inlet profile is fixed for all cases, however the relative layer thickness is modified to account for the mass balance. Therefore, the burden distribution patterns are distinguished by shifting up or down the curves for ore and coke volume fractions. The coke and ore radial diameter distribution is presented in Fig. 2 and is fixed for all calculations carried out in this study. The composition of the fuels used 


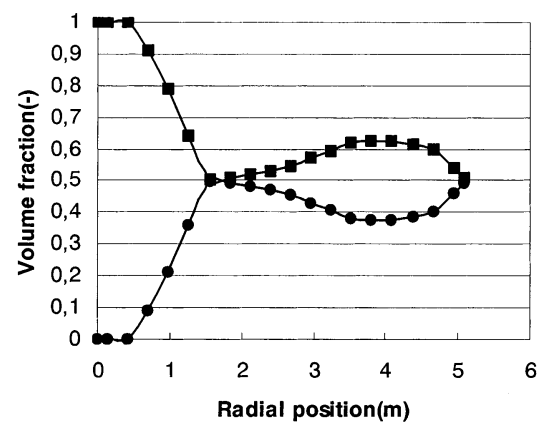

(A) Coke

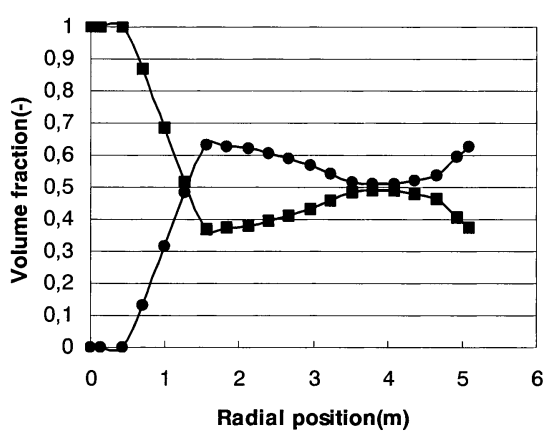

(C) Natural gas

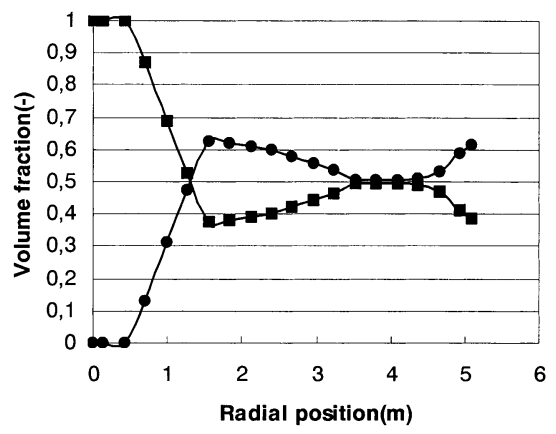

(B) Pulverized coal

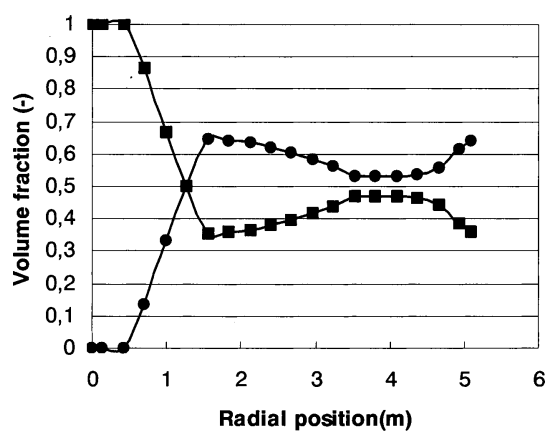

(D) Natural gas and pulverized coal

Fig. 1. Burden distribution pattern used for analyzing the multiple injection.

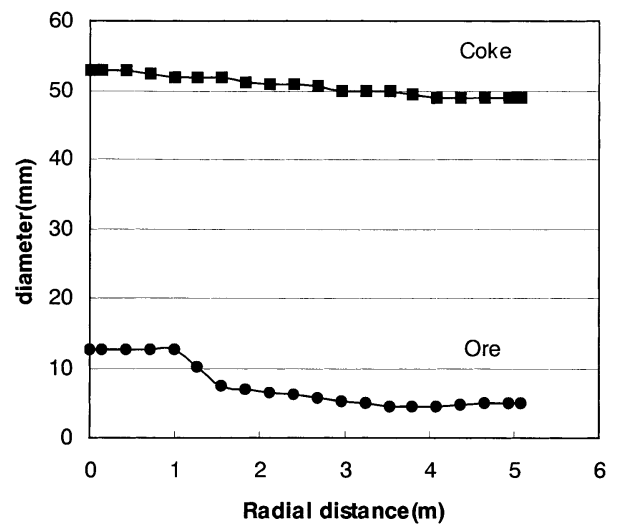

Fig. 2. Radial distribution of solids charged to the blast furnace.

Table 5. Chemical composition of natural gas and pulverized coal used in this study.

\begin{tabular}{|c|c|c|c|c|c|}
\hline \multicolumn{2}{|c|}{ Natural gas } & \multicolumn{2}{c|}{ Pulverized coal } & \multicolumn{2}{c|}{ Coke } \\
\hline Components & Mass (\%) & Components & Mass (\%) & Components & Mass (\%) \\
\hline $\mathrm{CH}_{4}$ & 90.1 & C (fixed) & 59.5 & C (fixed) & 84.86 \\
\hline $\mathrm{C}_{2} \mathrm{H}_{6}$ & 5.2 & Volatiles & 33.0 & $\mathrm{CaO}$ & 0.20 \\
\hline $\mathrm{C}_{3} \mathrm{H}_{8}$ & 1.3 & $\mathrm{CaO}$ & 0.2 & $\mathrm{SiO}_{2}$ & 6.01 \\
\hline $\mathrm{C}_{4} \mathrm{H}_{10}$ & 0.6 & $\mathrm{SiO}_{2}$ & 5.0 & $\mathrm{MgO}$ & 0.10 \\
\hline $\mathrm{N}_{2}$ & 2.6 & $\mathrm{MgO}$ & 0.1 & $\mathrm{Al}_{2} \mathrm{O}_{3}$ & 3.50 \\
\hline Others & 0.2 & $\mathrm{Al}_{2} \mathrm{O}_{3}$ & 2.2 & $\mathrm{H}_{2} \mathrm{O}$ & 4.04 \\
\hline
\end{tabular}

in this investigation is summarized in Table 5. The natural gas is mainly composed of methane, ethane, butane and propane. The calculation is performed as follows. A base case where only coke was calculated and assumed as the reference for the hot metal temperature and the remained cases were calculated by "trial and error" as follows: 1)
Natural gas and oxygen is added to the blast and calculation is carried out. 2) The computed hot metal temperature is compared with that one predicted to the all coke operation case. 3) If the difference between the predicted hot metal temperature and the base case (all coke) is larger than $10 \mathrm{~K}$, the amount of oxygen added to the blast is then adjusted and the calculation is performed again until the two predicted temperature being close enough (less than $10 \mathrm{~K}$ ). Same procedure is adopted to the pulverized coal and the combination of pulverized coal and natural gas, therefore the temperature of the hot metal for all cases are nearly kept constant while the other operational parameters are modified.

\subsection{Operational Parameters under Multiple Injection}

In this section, the main operational parameters for the multiple injection are investigated. Variations of main operational parameters are shown in Fig. 3. Figure 3(A) shows the oxygen enrichment used for the four cases analyzed. The needs of oxygen increases strongly for the cases of natural gas and the combined injection. The reason for such high oxygen enrichment is due to the need of keeping the hot metal temperature. Figure 3(B) shows the specific blast rate $\left(\mathrm{Nm}^{3} / \mathrm{thm}\right)$ used for the all cases investigated. The specific blast rate decreases for the cases of high injection of natural gas due to the increase of oxygen enrichment and consequent increase of the production rate. However, although the specific blast flow rate $\left(\mathrm{Nm}^{3} / \mathrm{thm}\right)$ decreases, the total amount of blast increases $\left(\mathrm{Nm}^{3} / \mathrm{h}\right)$. The effect of the injection on the productivity of the furnace is presented in Fig. 3(C). The productivity slightly increases for the pulverized coal and strongly increases for the high injection of natural gas cases. The increase of the productivity for the cases of high amount of injection is due to the high demand 


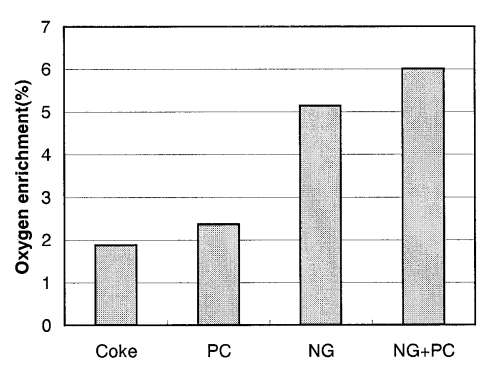

(A) Oxygen

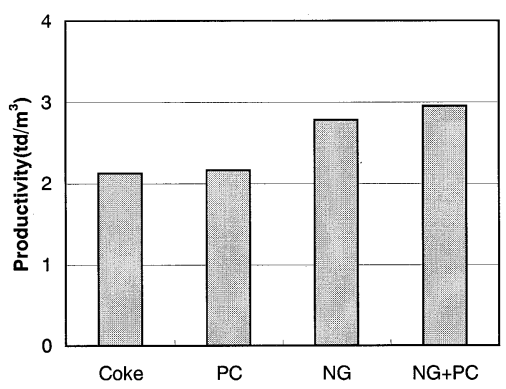

(C) Productivity

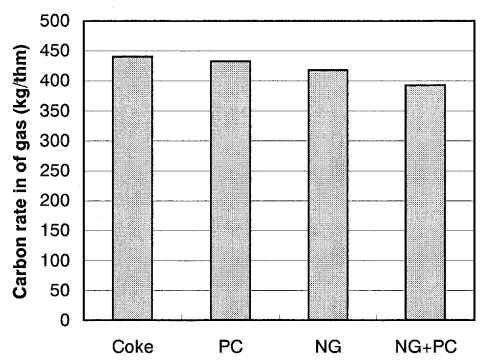

(E) Carbon emission

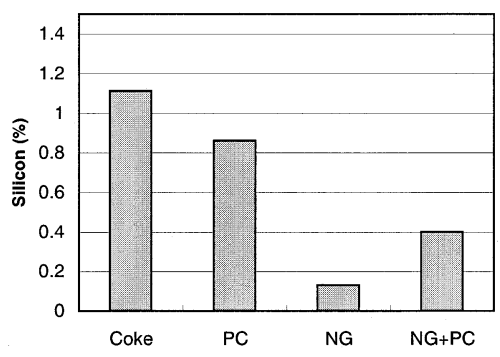

(G) Silicon content

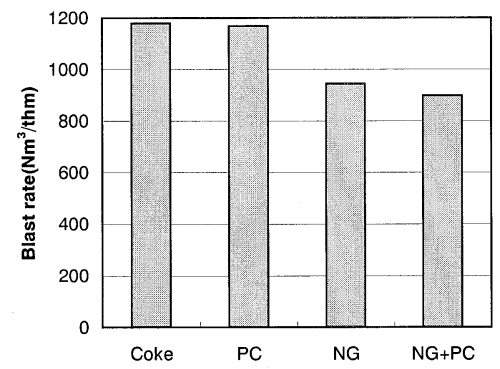

(B) Blast rate

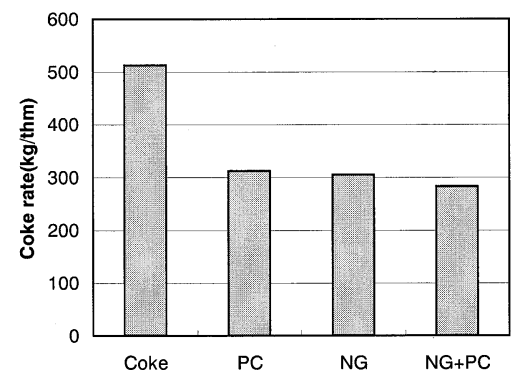

(D) Coke rate

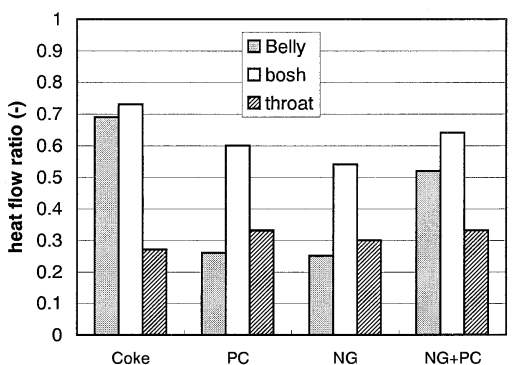

(F) Heat flow ratio

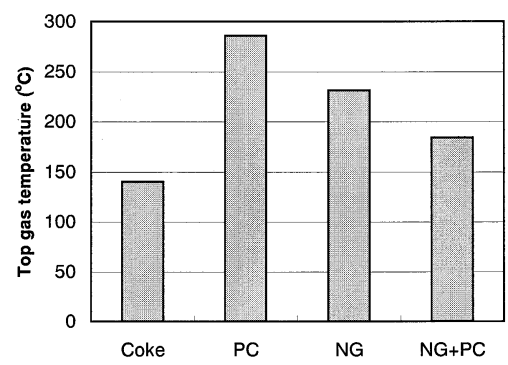

(H) Gas temperature

Fig. 3. Predicted operational parameters for multiple injection.

of oxygen and the drastic changes of the ore/coke ratio of the burden materials which are the result of the changes of the internal phenomena taking place within the blast furnace like chemical reactions knetics, momentum transfer and variables distribution patterns. The productivity increases largely for both cases of natural gas considered. The productivity increases to around $2.2,2.7$ and $2.9 \mathrm{t} / \mathrm{day} / \mathrm{m}^{3}$ when pulverized coal, natural gas and the simultaneous injection was injected, respectively. Increase of the productivity can be explained considering the following mechanism: a) The large amount of oxygen added to the blast for these cases. b) The increase of the ore ratio into the charged materials. The consumption of the coke in the raceway makes the inflow rate of iron bearing materials increase, since the ore/coke ratio charged was increased. Figure 3(D) shows the effect of multiple injection on the coke rate. The coke rate decreases for all injection cases investigated. The coke rate for the injection practices drastically decrease when pulverized coal or natural gas is injected. However the natural gas injection has a stronger effect to reduce the coke rate, in spite of the fuel rate slightly increases. The pulverized coal and natural gas replace the coke as reductant, decreasing the coke consumption. For the case of pulverized coal the coke rate decreases to around $308 \mathrm{~kg} / \mathrm{thm}$. For natural gas injection the coke rate decrease to around $304 \mathrm{~kg} / \mathrm{thm}$ and further decreased to around $282 \mathrm{~kg} /$ thm was 
obtained for the simultaneous injection. Decrease in the coke rate is due to the replacement of the coke by the injected materials and the thermal effect of changing the inner pattern of the blast furnace variables such as temperature, fractional reduction, thermophysical properties of the phases and so on. Therefore, main reasons for decreasing the coke rate are the replacement of the carbon of the coke by the carbon provided from the injection of carbonaceous material and the decrease of the energy demand within the blast furnace. In Fig. 3(E) is observed a considerable decrease of the carbon emission in the exit gas. This is an important parameter, since it represents the amount of greenhouses emission of the process. The addition of natural gas replaces the reduction with carbon monoxide by hydrogen and generates water which is environmentally clean, which is a great advantage compared with the conventional operation (all coke). Figure 3(F) shows the effect of the injection on the heat flow ratio of the bosh, belly and throat regions. The heat flow ratio decreases for pulverized coal and natural gas cases at the bosh region while slightly increases at the throat. Is important to observe that in spite of the gas volume increases the changes of the average heat capacity of the solids and gas phases together with the increase in the solid flow rate for the injection cases, the heat flow ratio in general decreases. The heat flow ratio in the throat was calculated as for bosh and belly, as the result of the integral equation .

$$
\mathrm{HFR}=\frac{\int \rho_{\mathrm{s}} C_{\mathrm{ps}} \vec{U}_{\mathrm{s}} T_{\mathrm{s}} d \vec{A}}{\int \rho_{\mathrm{g}} C_{\mathrm{pg}} \vec{U}_{\mathrm{g}} T_{\mathrm{g}} d \vec{A}} .
$$

Normally, the number usually known of the operators is calculated based on the average value of density, heat capacity, velocity and temperature. The number calculated by the above formula is a better representation of the inner phenomena and as the calculation is same for all cases, this represents a comparative parameter to be used in order to confront the cases analyzed.

In Fig. 3(G) was pointed out the considerable decreases of the silicon content of the hot metal, which could reach less than $0.2 \%$ for the natural gas injection. The reason for such decreasing is mainly due to the temperature decrease of the lower part of the blast furnace together with less generation of $\mathrm{SiO}$ gas from the coke and pulverized coal. Also the temperature of the top gas showed considerable increases for the pulverized coal and start to decrease for the other cases, but still being higher when compared with the base case. From these results the most important results were those regard to the productivity which could be increased about $30 \%$ for the high injection rate cases and the decrease of the emissions of pollutants which could be decreased about $10 \%$. The environmental benefit of this operation practice is clear, since water vapor is generated instead of the greenhouses $\mathrm{CO}$ and $\mathrm{CO}_{2}$ from the indirect reduction of iron oxides.

\subsection{Comparison of the In-furnace Conditions under Multiple Injection}

Figure 4 shows the temperature distributions for the gas phase in the blast furnace for "all coke", pulverized coal, natural gas and natural gas combined with pulverized coal cases. The isotherms of pulverized coal case are shifted up in comparison with the "all coke" operation. The pulverized coal burned in the raceway generates higher amount of hot gas which improve the heat exchange in the lower part of the furnace, in addition the ore/coke ratio increases and demands less energy to heat up the burden materials since the average heat capacity of the burden materials decreases. The combustion of natural gas releases less energy and cools the raceway, however large amount of oxygen was added to the blast to compensate this phenomena. Therefore the isotherms for the natural gas case are shift up in the upper part of the blast furnace and in the lower part the temperature is lower. Also for this case the ore/coke ratio was increased which reduce the amount of energy demanded to heat up the solids. For the case of simultaneous injection of natural gas and pulverized coal, the isotherms of the furnace were situated in an intermediary position compared with the pulverized coal and natural gas cases, since the effect of natural gas and pulverized coal injections are contrary. The increase in gas volume promotes higher interphase heat transfer and allows improvement on the reaction rates, increasing the performance of the reactor. The mass fractions of the hydrogen in the gas phase, for the analyzed cases, are presented in Fig. 5. The hydrogen in the "all coke case" is very small compared with natural gas and pulverized coal. On the contrary, for the natural gas and pulverized coal cases, a large amount of hydrogen is generated in the raceway region. Therefore higher mass fraction of the hydrogen in the gas phase is observed for these cases. The hydrogen is used as reducing gas in the shaft, therefore the mass fraction of hydrogen decreases at the upper part of the blast furnace due to the hydrogen consumption for indirect reduction. Figure 6 shows the fractional reduction pattern within the blast furnace for the cases analyzed in this study. For "all coke" operation strong variation of the fractional reduction profile is observed just above the cohesive zone. This is because the strong reaction rates of reduction in this region, which strongly relates with the temperature pattern. For the pulverized coal case the fractional reduction pattern is slightly shift up while for the natural gas case this is strongly shift up due to the strong reduction by hydrogen which takes place in the shaft. For the combined injection, the fractional reduction curves are located at the intermediate position following the temperature pattern. The gas density represents a strong link among the internal phenomena which occurs within the blast furnace and exemplify the strong changes of the physical properties when the injection of carbonaceous is performed. Figure 7 shows the effects of carbonaceous injection on the density of the gas phase. The gas density is estimated by using the assumption of ideal gas, which relates the density with the gas composition, pressure and temperature. For pulverized coal and natural gas injection the density of the gas phase decreases compared with the base case, while the combined injection shows intermediary pattern. The limitations for increasing the amount of pulverized coal and natural gas are mainly due to the resistance to the gas flow due to decrease of the bed porosity and large amount of liquid generation in the lower part of the blast furnace. However, the operation of 


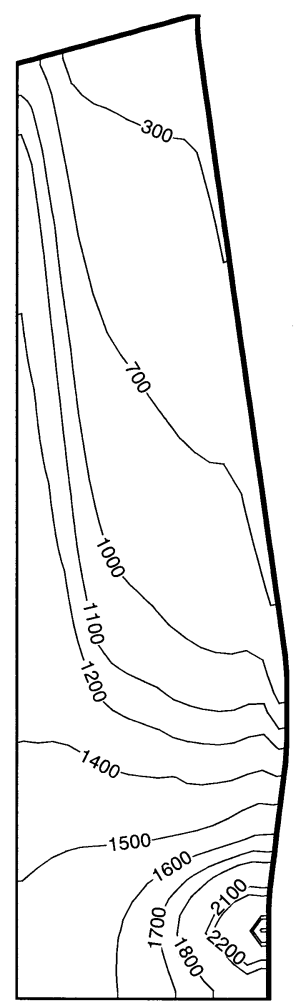

(A) Coke

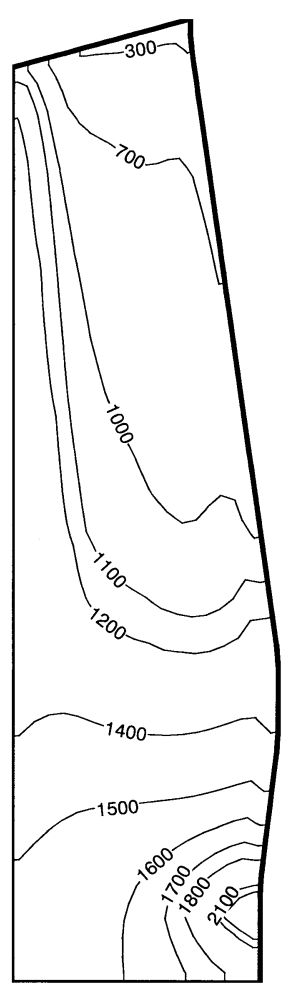

(B) pulverized coal

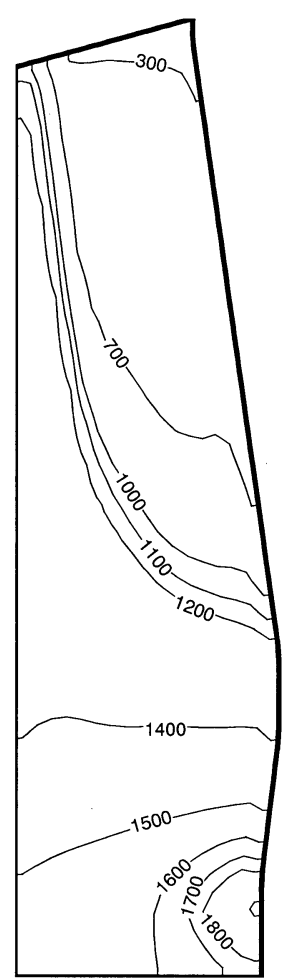

(C) Natural gas

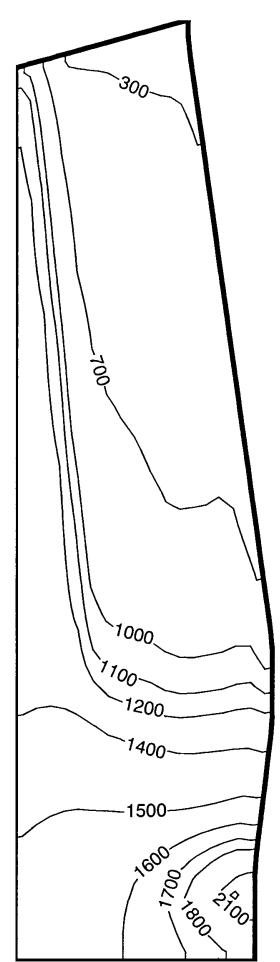

(D) Pulverized coal and natural gas

Fig. 4. Temperature distributions for the cases of multiple injection analyzed (unit: ${ }^{\circ} \mathrm{C}$ ).

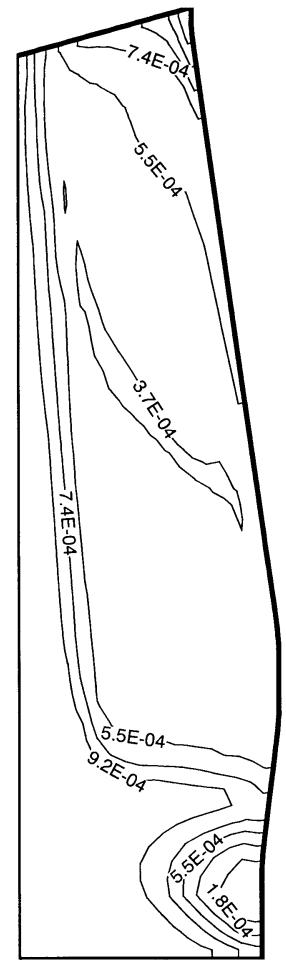

(A) Coke

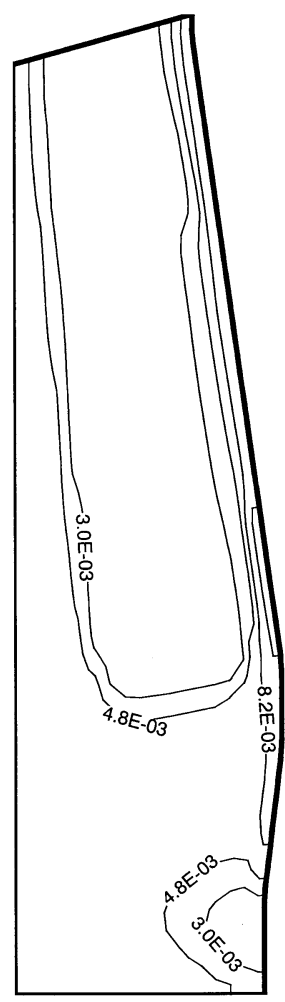

(B) Pulverized coal

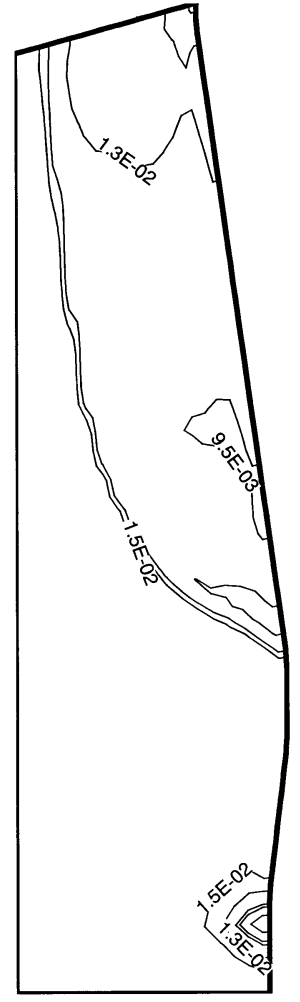

(C) Natural gas

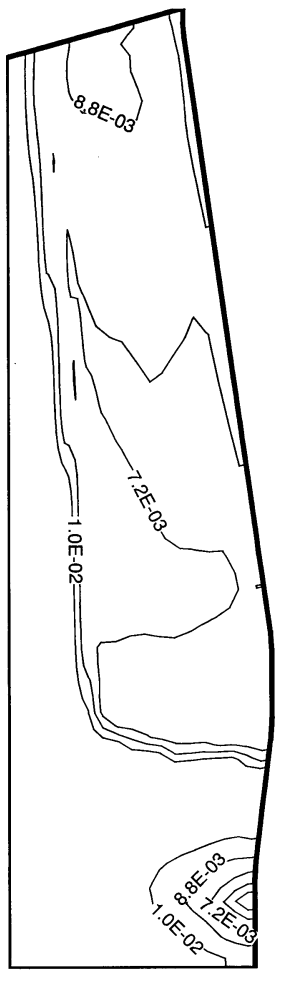

(D) Pulverized coal and natural gas

Fig. 5. Hydrogen mass fraction distribution in the gas phase (unit: -).

the blast furnace with low slag rate and efficient indirect reduction at the shaft allows the increase in the productivity keeping stable the blast furnace operation. This is the case of combined injection of natural gas and pulverized coal. While the pulverized coal furnishes the necessary energy to the lower part of the blast furnace, the natural gas furnishes 


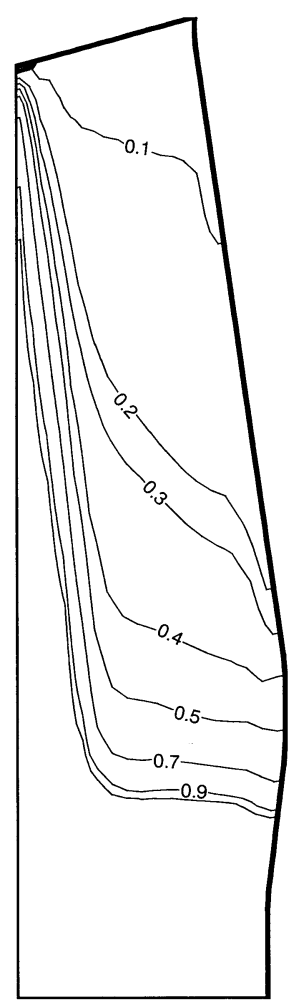

(A) Coke

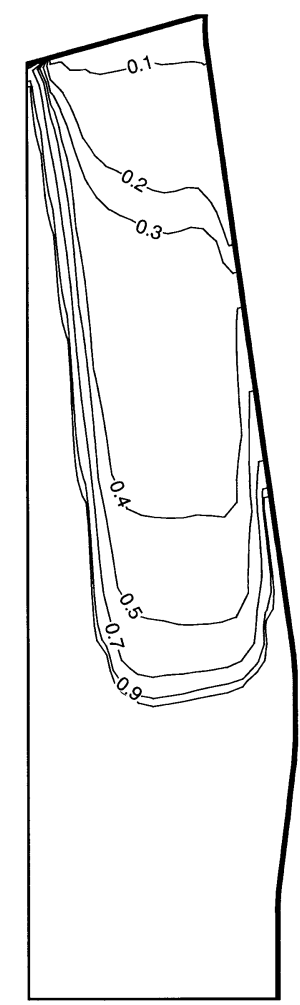

(B) Pulverized coal

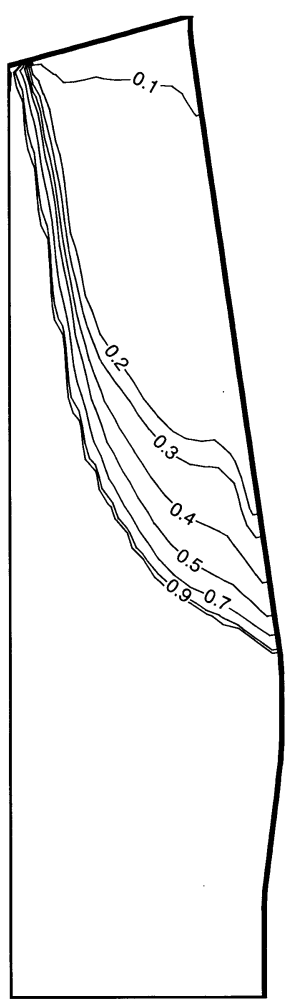

(C) Natural gas

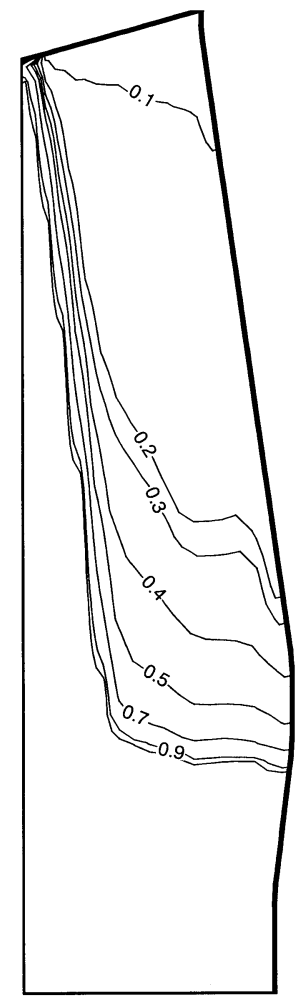

(D) Pulverized coal and natural gas

Fig. 6. Fractional reduction distribution (unit:-).

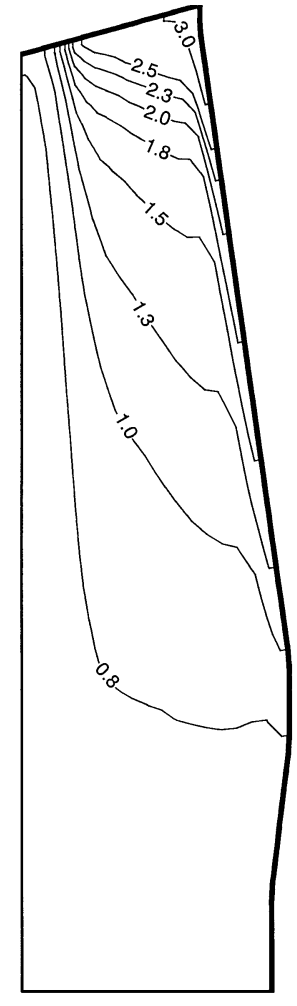

(A) Coke

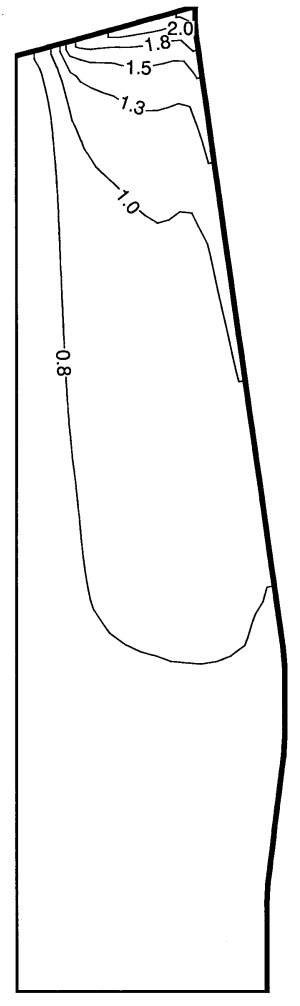

(B) Pulverized coal

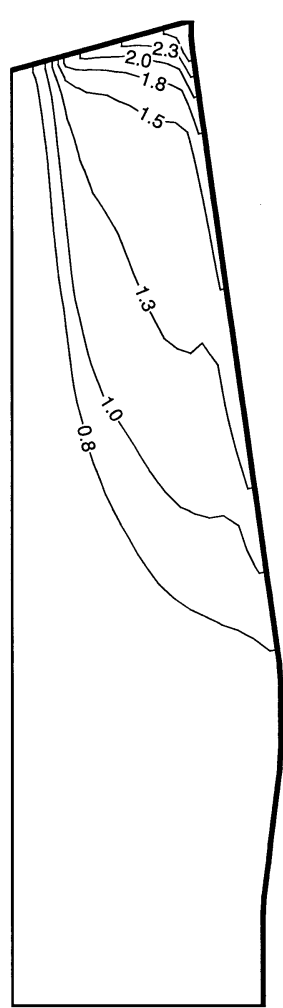

(C) Natural gas

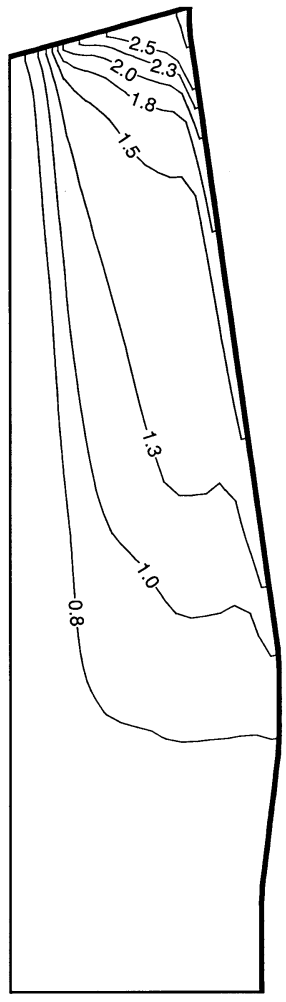

(D) Pulverized coal and natural gas

Fig. 7. Gas phase density distributions for the analyzed cases (unit: $\mathrm{kg} / \mathrm{m}^{3}$ ).

hydrogen to reduce the iron bearing materials in the upper part. In addition, increases of the superficial gas velocity improve the rates of chemical reactions and the inter-phase heat exchange, ${ }^{11,12)}$ improving the blast furnace performance. However, care must be taken regarding to the locally fluidization phenomena, which may occurs if the gas ve- 


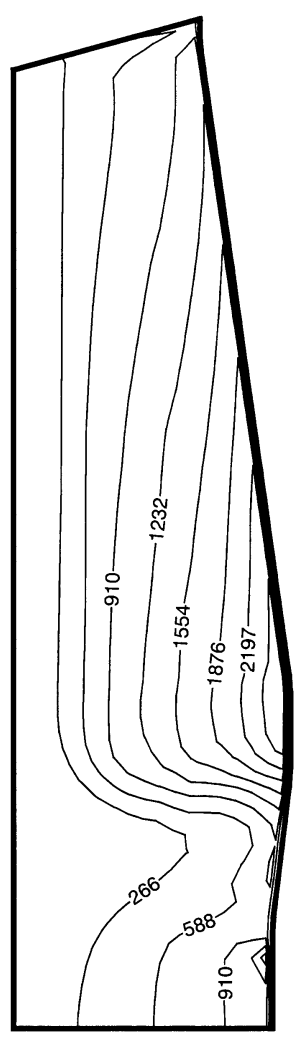

Fig. 8. Force balance for the case of high injection rate of pulverized coal and natural gas (unit: $\mathrm{N}$ ).

locity reaches the critical value corresponding to the necessary force to hung up the solids. For all the calculations performed in this investigation the fluidization phenomena did not take place. Figure 8 shows the resultant force distribution which is the result of all forces acting on the solid phase, including the gravity. The results shows a decrease of the resultant force acting on the solid phase at the central region due to the increase of the gas velocity and the decrease of the solid density and volume fraction, since only coke was charged in the central region, however it is lower than the minimum necessary to promote the fluidization (zero), which represents the equilibrium of all forces acting on the solid phase. Therefore the fluidization condition was not achieved for the most severe case, which is the simultaneous injection of natural gas and pulverized coal.

\section{Conclusions}

A mathematical model of the blast furnace has been developed which simulate the blast furnace operation under simultaneous injection of pulverized coal and natural gas with oxygen enrichment. The model considers multiphase chemical reactions with rates calculated by kinetic equations. The hot metal temperature was kept nearly constant in all cases to examine the effect of multiple injection while the blast composition and injection rates were adjusted.

Simulation results have shown that the productivity of the blast furnace can be largely increased by means of multiple injection of pulverized coal and natural gas. In this study was found that the blast furnace productivity can increase up to $2.9 \mathrm{t} / \mathrm{day} / \mathrm{m}^{3}$, representing an increasing of around $30 \%$ on the actual productivity of the blast furnace. The coke rate was decreased to about $280 \mathrm{~kg} / \mathrm{thm}$. In addition, the carbon emission as $\mathrm{CO}$ and $\mathrm{CO}_{2}$ are reduced to around $380 \mathrm{~kg} / \mathrm{thm}$, which contributes to make the blast furnace process cleaner.

\section{Nomenclature}

$k_{i}$ : Rate constant (various)

HFR: Heat flow ratio (-)

$P_{i}$ : $\quad$ Partial pressure of $i$ component (-)

$R:$ Gas constant $(\mathrm{J} / \mathrm{kmol} \cdot \mathrm{K})$

$R_{i}:$ Reaction rate $\left(\mathrm{kmol} / \mathrm{m}^{3} \cdot \mathrm{s}\right)$

$t$ : Time (s)

$T_{\mathrm{g}}: \quad$ Gas temperature $(\mathrm{K})$

$\vec{V}$ : Phase velocity vector $(\mathrm{m} / \mathrm{s})$

Greek symbols

$\Gamma_{\phi}: \quad$ Effective diffusion coefficient for variable $\phi(-)$

$\varepsilon_{i}:$ Phase volume fraction $(-)$

$\rho_{i}$ : Phase density $\left(\mathrm{kg} / \mathrm{m}^{3}\right)$

\section{REFERENCES}

1) A. Babich, S. Yaroshevskii, A. Formoso, A. Cores, L. Garcia and V. Nozdrachev: ISIJ Int., 39 (1999), 229.

2) J. M. Steiler: ICSTI/Ironmaking Conf. Proc., Vol. 57, ISS, Warrendale, PA, (1998), 343.

3) J. C. Agarwal, F. C. Brown, D. L. Chin, G. S. Stevens, F. C. Gambol and D. M. Smith: ICSTI/Ironmaking Conf. Proc., Vol. 57, ISS, Warrendale, PA, (1998), 443.

4) J. C. Agarwal, F. C. Brown, D. L. Chin, G. S. Stevens and D. M. Smith: ICSTI/Ironmaking Conf. Proc., Vol. 57, ISS, Warrendale, PA, (1998), 105.

5) O. Lingiardi, O. Burrai, C. G Fuentealba, P. Etchevarne and J. M. Gonzalez: ICSTI/ Ironmaking Conf. Proc., Vol. 57, ISS, Warrendale, PA, (1999), 135.

6) P. R. Austin, H. Nogami and J. Yagi: ISIJ Int., 37 (1997), 458

7) J. A. Castro, H. Nogami and J. Yagi: ISIJ Int., 40 (2000), 637.

8) P. R. Austin, H. Nogami and J. Yagi: ISIJ Int., 37 (1997), 748.

9) R. H. Perry and D. Green: Perry's Chemical Engineers Handbook, 6th Ed., McGraw-Hill, New York, (1984), Table 3-5.

10) Kagaku Kogaku Binran (5th ed.), ed. by Soc. Chem. Eng., Japan, Maruzen, Tokyo, (1988), 232.

11) V. Ya. Basevich: Prog. Energy Combust. Sci., 13 (1987), 199.

12) W. E. Ranz and W. R. Marshall: Chem. Eng. Prog., 48 (1952), 141, 173.

13) T. Akiyama, R. Takahashi and J. Yagi: ISIJ Int., 33 (1993), 703. 